\title{
Framing cognition: Dewey's potential contributions to some enactivist issues
}

\section{Roberta Dreon ${ }^{1}$}

Received: 25 August 2018 / Accepted: 13 April 2019

(c) Springer Nature B.V. 2019

\begin{abstract}
It is well known that John Dewey was very far from embracing the traditional idea of cognition as something happening inside one's own mind and consisting in a pictorial representation of the alleged purely external reality out there. His position was largely convergent with enactivist accounts of cognition as something based in life and consisting in human actions within a natural environment. The paper considers Dewey's conception of cognition by focusing on its potential contributions to the current debate with enactivism. It claims that Dewey's anti-substantial, continuistic, and emergentistic conception of the mind as a typically human conduct pulls the rug out of the idea of cognition as representation, as well as pushes the current discussion towards a serious reconsideration of representationalist assumptions about conceptuality and language. The paper emphasises that Dewey-differently from enactivists-frames the role of cognition within experience: he argues that cognition concerns those intermediate phases of our experiences of the world which are characterised by an indeterminate or troubled situation, because he claims that human beings' interactions with their own environment are qualitatively richer and broader than cognition, including as they do many different and intertwined modes of experience. Finally, the author suggests that a coherent development of Dewey's lines of thought should avoid rigid distinctions and hierarchies between lower and higher degrees of cognition in humans, which are still maintained in certain forms of radical enactivism. Differently, we should consider the impact of the cultural and broadly linguistic configuration of the human-environment even on perception, motor action, and affective sensibility.
\end{abstract}

Keywords John Dewey $\cdot$ Enactivism $\cdot$ Cognition $\cdot$ Experience $\cdot$ Mind

A lot of water has flowed under the bridge of philosophical debate since Francisco Varela, Evan Thompson and Eleanor Rosch presented their 'pragmatic' conception of embodied cognition as a defining feature of enactivism without ever referring

Roberta Dreon

robdre@unive.it

1 Department of Philosophy and Cultural Heritage, Ca' Foscari University, Venice, Italy 
to the tradition of classical American pragmatism. ${ }^{1}$ As is widely known, the major philosophical tradition which enactivism has drawn upon from the very beginning is phenomenology - especially Merleau-Ponty, but also the late (and unwittingly antiCartesian) Husserl and Heidegger's existential analytics.

An explicit engagement with the classical pragmatists, especially John Dewey and Herbert Mead, was launched and entertained by many leading voices in the critical debate on the cognitive sciences, generally brought together under the $4 \mathrm{E}$ label, namely the supporters of the embodied, embedded, extended and enactive theories on cognition and the mind. ${ }^{2}$ In particular, Shaun Gallagher has offered an analysis of Dewey's positions, devoting many pages of his book Enactivist Interventions (Gallagher 2017, p. 48 ff.) to it. The time is ripe now to consider not just the significant convergences between enactivism and pragmatism, but also to promote a fruitful engagement with pragmatist reflections. The latter, while probably difficult to translate into applied research plans, can offer not just confirmation or anticipations, but also some challenging stimuli. Roughly speaking, it is a matter of understanding not just what classical pragmatism has to offer enactivism, but also what the latter can learn from pragmatism through an open and mutual engagement. ${ }^{3}$

The present paper seeks to make a small contribution towards this kind of work, by considering certain aspects of Dewey's approach to cognition that-in brief-go beyond the evident convergences with regard to the enactive, fully embodied aspect of cognition, understood as being embedded in a natural and social environment according to a process of mutual configuration between the mind and the world. More specifically, I would like to offer first of all (1) an outline of the conception of the mind developed by the American pragmatist. As is widely known, a recurrent and central feature of enactivism in its various forms is the criticism of representationalis$\mathrm{m}$-in brief, both in its mentalistic version, according to which knowledge consists in the manipulation of mental states, and in its representationalist version, as the physicist assumption that cognition consists in the computation of neural processes capable of conveying informative contents regarding the external world. ${ }^{4}$ The point is that criticism of mentalism entails a profound redefinition of the Cartesian metaphysical assumption that the mind is something ontologically different from the external world and, correlatively, that the reality to be known is out there, as something that is foreign

\footnotetext{
1 The 1991 volume (Varela et al. 1991) makes various references (in the notes, the bibliography, and part of the text itself) to authors from the heterogeneous tradition of neo-pragmatism, such as Hilary Putnam, Richard Rorty, Richard Bernstein and Joseph Margolis, who nonetheless are not identified as pragmatists. As already noted, the text makes not reference to the authors of classical American pragmatism, including William James. On the differences in the use of the adjective "pragmatic" and "pragmatist" in enactivist literature, see the interesting article by Steiner (2017).

2 See, among other works, Johnson (2010) and Menary (2015). On the mutual engagement between pragmatism and the cognitivist sciences, see too the volumes edited by Solymosi and Shook (2014) and by Madzia and Jung (2016). The topic has also been the focus of an issue of the journal Pragmatism Today (Madzia and Santarelli [Eds.] 2017).

3 Some serious work engaging with the cognitive sciences on the basis of classical pragmatism has been carried out by Pierre Steiner in recent years. See Steiner $(2008,2014,2017)$.

4 By contrast, here I will not address the thorny issue of the ways in which mental states are correlated with neural processes, which is to say of the way in which semantic contents might be embedded within a syntactic system (on this see Steiner 2014).
} 
to the knower because it is already self-defined. Therefore, cognition would consist in the faithful mirroring of the states of things by mental states (Varela et al. 1991, p. 40). In other words, enactivism implies an alternative philosophy of mind-if not a philosophy of nature and of the role of the mind in nature, as explicitly acknowledged by Gallagher (2017, p. 21). I believe that Dewey indeed offers something of the sort, insofar as his deflationist and anti-substantialist (I), genetic and emergentist (II), and functionalist (III) account of the mind, developed within the framework of an underlying continuity between the mind and life phenomena, undermines the fallacious foundations at the basis of mentalistic dogmatism-without thereby entailing the need for discarding words such as 'mind', 'mental' or even 'representation', which is something utterly foreign to pragmatist pluralism. It no longer makes much sense to ask oneself whether cognition essentially or partially presupposes representative mental states, if the mind is conceived as a peculiar form taken by interactions between organisms and their environment with the development of the typically human form of life.

At the same time, Dewey might not yet have agreed with a non-mentalistic interpretation of representationalism, namely with the assumption that cognition is a matter of managing intracranial contentful states. In his Introduction to the Essays in Experimental Logic, he clearly states that thinking is not an "event going on exclusively within the cortex" (Dewey 2004: p. 2). Foreshadowing more recent radical embodied and extended views of cognition, he argues that "Hands and feet, apparatus and appliances of all kinds are as much a part of it as changes in the brain" (Dewey 2004: p. 2), including words and social procedures to explore the world. Knowing is not a matter of neural processing happening within the brain: it is a mode of acting and undergoing of the human organism in its entirety in the natural and naturally social environment (see also Dewey 1980a: p. 26). ${ }^{5}$ In a Deweyan vein, I suggest, events unfolding "within the cortex" should be considered as neural resources for the active engagement of the human organism with its environment and in continuity with other bodily and environmental resources, rather than as mental representations.

Secondly, (2) I would like to stress one important difference between Dewey's approach and enactivism with regard to cognition. Dewey too, long before the enactivists, conceived human cognition starting from life and from the fact that living organisms are structurally dependent on their environment for survival at all levels - from mere biological preservation to cultural and social development (Dewey 1980a, pp. 7, 26 and ff.; 1989, p. 18 and ff.; 1991, p. 26). On the other hand, an organism's structural interactions with its environment will modify the latter to varying degrees and contribute to reconfiguring it from within, since the organism is an integral part of the natural environment, which is always subject to dynamic change (Dewey 1980a, pp. 7, 15 and ff.; 1983, p. 16). ${ }^{6}$

\footnotetext{
5 I am grateful to Pierre Steiner, who at a seminar he gave in Venice in December 2018 brought to my attention the fact that in current cognitive sciences there are also non-mentalistic representationalist positions, which support an eliminativist approach to the mental and consider contentful states of the brain as having nothing whatsoever to do with representative functions, in the metaphorical sense of the term-insfoar as these states do not stay for or mirror extracranial states of things.

6 This kind of approach takes as its starting point not a disembodied awareness dealing with a reality that exists out there, even prior to any human intervention, but rather an organism which finds itself in an
} 
However, Dewey constantly upholds the idea that cognition does not include the whole range of interactions between organisms and the environment, not even in the case of human interactions (Dewey 1981, p. 28). Dewey speaks of experience as the sum of interactions between living human beings and their natural and naturally social environment (Dewey 1981, p. 132 and ff.; 1983, p. 44), whereas he only applies the terms "cognition" and "inquiry" to certain stages or parts of experience, to refer to the cognitive process underway (Dewey 2004, p. 12 and ff.; 1991, p. 105 and ff.). In Dewey's case, the return of studies on cognition to lived experience-a turn welcomed by the enactivists (Varela et al. 1991, p. XV; Colombetti 2014, p. XV)—entails an acknowledgement that human experience is far richer and thicker than the cognitive aspects and processes unfolding within it. Although Dewey assigns a crucial role to the potential of human reason-on a political and ethical as well as metaphysical level-inquiry represents an intermediate stage within experience. As a whole, experience is constituted by the sum of concrete interactions in progress within the world rather than in the alleged inner theatre of the individual-namely, within a natural and markedly social environment that is prior to the individual's birth (Dewey 1983, p. 45). As a process, cognition concerns the critical stages of experience (Dewey 2004, p. 1 ff.; 1981, p. $100 \mathrm{ff}$; 1991), where the situation ${ }^{7}$ in which the organism and the environment find themselves freezes as the individual does not know what to do, an obstacle presents itself, ${ }^{8}$ established habits of conduct do not work, and the need is felt for a kind of reflection capable of analytically examining the various components of an indeterminate situation to find a suitable course of action.

Dewey would not have accepted the maximum extension of the notion of cognition, namely the enactivist thesis that all living systems are cognitive systems, in the sense that "in virtue of their adaptive autonomous organization, they behave according to meanings and norms that they themselves bring forth (generate) in interaction with the world [...] Cognition, in other words, is the activity of sense-making" (Colombetti 2014, p. 18). ${ }^{9}$

\section{Footnote 6 continued}

environment that precedes its individual existence, and of which it is at the same time an integral part. The organism, in turn, modifies this environment and dynamically reconfigures it from within. An approach of this sort allows Deweyan pragmatism to avoid the fruitless opposition between naive realism and idealism. In other words, this perspective makes it possible to avoid the opposition between the assumption of a reality that is already entirely predetermined, and which the knower must strive to faithfully mirror, and the assumption that reality is merely a subjective construct. See Hildebrand (2003). Somewhat similar claims are made in the chapter on "Cartesian Anxiety" in the volume by Varela et al. (1991, p. $133 \mathrm{ff}$.). Significantly, this formula was first used by Richard Bernstein, who was one of the few pragmatists at a time when this tradition was almost entirely ignored in the United States.

7 For a more in-depth examination of Dewey's notion of situation, see Steiner $(2008, \S 3)$ and Gallagher (2017, p. 54 ff.).

8 Mead, who had worked closely with Dewey on these issues, also stressed the centrality of inhibition for understanding the specificity of intelligent human behaviour compared to other forms of animal intelligence. See esp. the essays What Social Objects Must Psychology Presuppose? Emotion and Instinct, and The Child and His Environment in Mead (2011).

9 On this point see the very clear view of Arteaga: "Obviously, the enactive concept of cognition implies an extension of the common meaning of this term. Cognition in this context is not reduced to the production, development or achievement of an explanation or a skill-in reference respectively to the concept of 'knowing that' and 'knowing how'_about something else: respectively an object or state of affairs or a task. Cognition is not reduced here to a mere question of problem-solving. To solve a concrete problem or 
Of course, we could say that this is simply a terminological difference: enactivists call "cognition" what Dewey called "experience", namely the whole intercourse of transactions and events occurring between an organism, continuous with the environment, and its own world - an effectively organic, cultural and social Erfahrung happening "out there" and not something like an Erlebnis that is an inner process occurring within one's own private mind or consciousness (Dewey 1980a, p. 18; 1989, p. 25 and ff.). However, I am afraid that this would not be a neutral translation of Dewey's point of view. First of all, if we adopt the word "cognition" as a synonym for "experience", how could we distinguish those phases of our interaction with the world around us where we do not try to make sense of things, but are simply overwhelmed by and absorbed (Dewey 1981, pp. 15, 22, 71, 82, 105; 1985, pp. 264-265) by what things, events and other people do to us, from more reflective cognitive phases? ${ }^{10}$

Moreover, by adopting the enactivist translation of living processes in terms of cognition, we would run the risk of neglecting the peculiarity of human interaction with the environment compared to other, non-human forms of interaction: the former type of interaction is not better in itself and is wholly contingent, yet it is certainly different if we take into account the loop effect of the emergent properties of a system on its previous forms of organisation. This restriction of the field of human cognition might have some positive consequences for enactivist research, and would certainly entail the need for a reorientation.

Finally, (3) I wish to argue that from a pragmatist standpoint (already according to Peirce's perspective, and even more so from Dewey's ${ }^{11}$ ) the distinction between basic cognitive processes and higher ones is problematic, as is the founding of the latter upon the former. This represents the central issue in the debate on whether we should include representational aspects in the case of higher cognitive processes, such as the imagination and memory, as opposed to perception and motor action, which instead would rule such aspects out completely (Hutto and Myin 2013, p. 13). This kind of distinction seems problematic within a human context characterised by an ecological niche that is already highly social, culturally stratified, and linguistic (in a broad sense). It also seems detrimental on account of the opposition it risks creating between a rigid and still representationalist idea of abstract conceptuality (as argued by Gallagher with reference to McDowell and Dreyfus in Gallagher 2017, p. 202. Cf. Zahavi 2013; Noë 2013) and a pre-cultural conception of human perception/action that is largely untenable, and which in turn appears to be the product of intellectual abstraction.

This does not mean that Dewey does not propose any other kind of distinction to characterise the wide range of interactions that we constantly experience. Dewey first

\section{Footnote 9 continued}

to develop the necessary skills to do it configure specific aspects of cognition but define neither exhaustively nor fundamentally this term. The enactive concept of cognition refers to the fundamental activities of being alive, of finding ways to maintain life, to preserve the viability of the living unit's active-being-in-the-world in and with the worlds that emerge out of life's own processes, which simultaneously enable living units to achieve and maintain their own selfness" (Arteaga 2017, p. 23).

10 On this issue see Dreon (2018).

11 See the 1868 essays Questions Concerning Certain Faculties Claimed for Man and Some Consequences of Four Incapacities (Peirce 1992a, b). The question of whether it is possible to draw a clear-cut distinction between perception and higher cognitive processes is also addressed by Mead in an essay entitled Concerning Animal Perception (in Mead 2011), which ultimately gives a negative answer. 
considers the possibility to distinguish between cognition as a process underway and knowledge as the results of previous inquiries, which become entrenched as habits of conduct and forms of qualitative sensibility guiding one's actions, rather than as mental representations (Dewey 6; Dewey 1981, pp. 39-40; 1991, pp. 121-122). The second distinction is between primary, qualitative or aesthetic experience, on the one hand, and the kind of experience that is reflective, analytical and properly cognitive, albeit according to highly variable degrees of concreteness.

One interesting point that enactivist research might draw upon is the fact that both of these distinctions are not substantial ones for Dewey, but only functional and contextual distinctions. In particular, the American pragmatist envisages a circular and non-foundational relation between qualitative experience, which is largely habitual and non-reflective, and ongoing inquiry. Therefore, cognition emerges not as the incipient and paradigmatic form of experience, but as an intermediate mode of extending the possibilities of experience designed to meet the needs of primary qualitative experience. On the other hand, inquiry retroacts on qualitative experience, enriches it with possible new meanings or impoverishes it, and modifies its very qualitative structure.

\section{The mind in action}

In 1912, in an essay entitled "What are States of Mind?", Dewey had already provided an embryonic critique of the foundations of mentalism, namely the assumption that cognitive processes consist in the manipulation of mental states (Dewey 1979). In that context, he suggested limiting the explicative power and function of mental states: with his distinctive tolerance, Dewey acknowledged that, in the retrospective analysis of a given behaviour, it is possible to distinguish between the organic reverberation and the psychic change that a given physical event engenders in us-between corporeal changes and the mental states associated with them. However, this distinction is introduced a posteriori. In other words, the distinction between a psychic or mental state and motor action is functional, not primary ${ }^{12}$ : it is due to the retrospective intervention of the analysis of a certain integral situation which for some reason becomes problematic and needs to be solved through the analytical abstraction and isolation of some of its components. The process of inquiry is designed to produce a change, somehow or other, in the organic and environmental conditions of the interaction, in order to engender a new dynamic balance. The problem emerges when the psychologist's analytical distinctions - the outcome of reflective analysis - are assigned a primary ontological status, whereby the abstractions in question acquire the role of primary constituents of behaviour, on the basis of which all experiential processes ought be understood, starting from cognitive ones. Therefore, to assume that cognitive processes primarily coincide with mental states, on which one's actions and conduct depend, is to commit a "retrospective fallacy", giving rise to a misleading dualism between mind and body, mental states and action, inner consciousness and external reality.

\footnotetext{
12 As other scholars have noted, a crucial work on this issue is the essay on the reflex arc that Dewey wrote as early as 1896 (Dewey 1972).
} 
Dewey was later to develop "an 'emergent' theory of mind" (Dewey 1981, p. 207), which de facto demolished the assumptions at the basis of representationalism in its mentalistic version. Just to make things clearer, in relation to the various levels of Dewey's discourse I will distinguish three arguments, suggesting that his account of the mind is deflationist and anti-substantialist (I), ${ }^{13}$ genetic and emergentist (II), and functionalist (III).

(I) The first defining feature of Dewey's interpretation is the idea that the adoption of the term "mind" as a noun is rather inappropriate and misleading. In a few interesting pages of a chapter of Art as Experience on the misunderstandings engendered in aesthetic theory by a series of fallacious psychological concepts, Dewey invites the reader to consider the idiomatic usages of "mind", which have a mostly verbal or adverbial character in everyday English, rather than its use as a noun (Dewey 1989, pp. 267-268). "Being reminded of something" means being made to remember something, "bringing mind on something" means paying attention to something. Dewey notes that such everyday uses tend to avoid hypostatising the mind as an entity that is separate or independent from reality, and to emphasise that we are exposed to facts, events and objects from the world. Moreover, the wide range of uses of the verb "to mind"- meaning to take care of something, to pay attention to the steps we are taking, or even to obey someone-shows that in everyday language the mental quality is not exclusively correlated with cognitive contexts, but also concerns the sphere of affects and of practical action. Excessive emphasis on the use of the verb as a noun tends to hypostatise the mind as an entity that is independent from the environment within-and with - which it acts. This entity would then unduly be adopted as the inner condition guiding the different ways of acting within the world. By contrast, Dewey believes that "the mental" coincides with the character, mode and quality of certain kinds of interaction between the specifically human form of life and the environment to which it belongs and on which it depends. From this perspective, Dewey rejects both the Cartesian tradition of the mind as a sui generis ontological substance compared to the extended substance, and the conception of British empiricist origin according to which the mind results from the association or combination of different perceptions, as well as from their mutual relations. ${ }^{14}$

(II) In order to formulate an alternative conception of the mind, Dewey sets out from "biological commonplaces" (Dewey 1989, p. 20), whereby each form of life interacts with its environment in different ways and to different degrees. It is bound to do so, since this is what being alive consists in: it is not at all the case that the subject is initially self-sufficient and faces the problem of his relationship with objects and other subjects only subsequently, following his self-determination. The human living being is an organism that finds itself immersed in an environment which includes as integral parts not just natural and cultural things and events, but also other organisms, on which the life of the human creature depends. This move of Dewey's-i.e. the choice to consider the mental quality starting from life phenomena-later also came to be

\footnotetext{
13 Pierre Steiner defines this approach to the mind as "adverbialist" in Steiner (2017).

14 See the 1908 essay The Logical Character of Ideas, reprinted in Essays in Experimental Logic in 1916 (Dewey 2004).
} 
shared by enactivism. ${ }^{15}$ It undermines from the very beginning the attempt to approach the question of knowledge as the problem of the mental mirroring of an allegedly external reality, but also the framing of the question of other people's experience as the problem of accessing their minds through the implicit adoption of a theory or by simulation - both these perspectives being based on a form of methodological individualism (cf. Gallagher 2017, p. 75). I will shortly return to this point.

In Experience and Nature (Dewey 1981), by adopting a continuist approach, Dewey notes that, compared to inanimate beings, living beings are characterised by the fact that their relations with the environment in which they exist are always biased (Dewey 1979) or interested, in the sense that living beings always tend to remain alive- they are not indifferent to the way in which environmental actions affect them, or to the consequences that their own activities have on their lives. Obviously, this occurs to more or less complex and refined degrees depending on the form of life under consideration. One important element of discontinuity is represented by the emergence of the capacity for (self-)motion and locomotion, which makes the first forms of postponement of satisfaction possible, along with the reference to something else that is not immediately present in the proximity of the organism. Dewey, like the enactivists, assumes motor-activity to be of primary importance for living organisms when it comes to making reference to something else. In turn, this is interpreted as a kind of active intervention in the environment or as an embodied semiosis. Selectivity and partiality, therefore, do not apply only to human beings, but also to animals - at any rate, animals capable of locomotion, because they are strictly connected to the practical capacity to reach something or someone that is not close. These develop a kind of sensibility that also implies a temporal structuring of interaction: instead of occurring immediately, interaction unfolds through a preparatory stage that is an anticipation and a stage of accomplishment (fulfilment), in which the action is completed (consummation). This basic continuity in embodied sense-making represents a further common point between the enactivists and Dewey. Nonetheless, according to Dewey, this way of structuring interactions is typical of more complex animal organisms, yet it is incapable of ensuring reflection-it is not mental, according to his use of the term, although it clearly implies various degrees of intelligence. It involves what the American philosopher calls "psycho-physical" activities and behaviours, insofar as the biological structures themselves entail a subtle selective sensibility, whereby things are discriminated and felt to be favourable or unfavourable, good or bad, even though, strictly speaking, they are not known. Feelings then become meanings in typical human interactions - but this does not mean that the process can be described as a teleological development from the inferior to the superior, which would be entirely out of keeping with Dewey's Darwinian interpretation (Dewey 2007; see too Cometti 2015), and with the emphasis on chance that is typical of all classical pragmatists (cf. Calcaterra 2011). With regard to this point, a substantial convergence is to be found with Varela, Thompson and Rosch's position on evolutionism (Varela et al. 1991, p. $185 \mathrm{ff}$.). These researchers strongly criticized the neo-Darwinian view of evolution centred on adaptation, considered as a telos (a "Mount Fittness", Varela et al. 1991,

15 Here a long series of references could be provided, starting from the fathers of enactivism: Varela et al. (1991), Hutto and Myin (2013), Colombetti (2014) and Gallagher (2017)— to quote but a few. 
p. 193) to be pursued by genes in a pre-determined environment, by adapting to the latter's allegedly already fixed constraints. On the contrary, they endorsed an idea of evolution as a "natural drift" (Varela et al. 1991, p. 201), while also emphasizing Richard Lewontin's idea that we should give up the assumption of the environment as separate from what organisms are and from what they do in it (Varela et al. 1991, p. 198). In Logic Dewey's conception of his own naturalism as "cultural naturalism" emphasized a similar point by considering that thinking and inquiries take place in an environment, which has become naturally cultural in the case of human beings (Dewey 1991, pp. 26-28).

Returning now to Dewey's argument in Experience and Nature, we need to address the following question: when and how do these forms of mental organisation of organic-environmental interactions emerge?

Keeping to the phylogenetic level of the interpretation of mental phenomena, ${ }^{16}$ the mental behaviour cannot be attributed to any innate instinct, nor can it be reduced to the neurological substrates that—out of all the corporeal and environmental resources available - constitute a crucial part of the organism. The "mental" is a quality of human interactions with the environment acquired over the course of a process of evolution. This process would have come about starting from pre-existing conditions-animal, yet not human, conditions - that were modified through the influence of an environment characterised by a marked dependence of the individual on the social group he belongs to, which is to say by the need to share activities, behaviours, habits and meanings that find in language the most powerful tool to establish a shared space and participate in it. Dewey goes so far as to argue that the mind is the by-product of a form of life that is structurally associated and conjoined with other organisms, which is to say characterised by forms of structural interdependence. The mind would consist in a series of primarily social and shared dispositions, beliefs, attitudes and behaviours, on the basis of which individual identities would emerge (cf. Dewey 1979, § 2). To clarify things with respect to the debate on representationalism and anti-representationalism, Dewey is not surreptitiously reproposing the idea that the mind contains beliefs and attitudes in the form of doxastic or intentional propositional contents: for Dewey, beliefs, attitudes and expectations are primarily more or less rigid or intelligent habits of action (cf. Dewey 1983), dispositions to act in the world and on the world-not films first projected in the alleged dark theatre hall of the individual mind, and then enacted in the street outside the cinema. Moreover, Dewey clearly champions the idea that personal identity emerges out of an already socialised environmental background, in which each individual learns to play his part within a shared context of associated living. Right from the start, therefore, Dewey reverses the notion that the experiencing of others occurs on the basis of an already fully developed individual mind, as assumed both by the formulation of a more or less naive theory of other people's minds, and by the attribution to other people of mental states similar to those experienced in first person via embodied simulation.

More in particular, according to Dewey the "mental" is a reflective mode of interaction with the environment, i.e. one capable of analytically dwelling upon indeterminate

16 See esp. the 1917 essay The Need for Social Psychology (Dewey 1980b), from which a very close collaboration with Mead may be inferred. 
situations, by distinguishing the salient parts of the experiential continuum, in order to determine a course of action. In other words, a mental behaviour implies the cognitive development of human experience, i.e. a reflective turn that extends human conduct to a wide range of possible behavioural alternatives, producing a cultural reconfiguration of the natural environment.

On the other hand, Dewey argues that the emergence of forms of reflective interaction in man entails the reuse of previous biological structures for new ends (Dewey 1981, p. 211). ${ }^{17}$ This means that the mind is continuous with nature, that it does not intervene in nature as an external element, transcending nature itself, but also that it is irreducible to other phases or modes of organic life. The mind, therefore, is a phase internal to nature, or at any rate irreducible to something prior to it, because it distinguishes itself and stands out from it owing to the new organisation of the organic-environmental interactions it consists of - an organisation that is not just more complex, but also qualitatively innovative, and irreducible to the sum of physical and biological aspects in which it becomes rooted. ${ }^{18}$

(III) Let us now bring the functional level of Dewey's account further into focus. ${ }^{19}$ He argues that the modes of interaction with the world are "mental" in the case of human forms of life, because we witness the emergence of processes of reflective or analytical reconsideration of how the individual is affected by the environment and on the ways in which, in turn, human organisms act, or can act, on the environment, thereby contributing to modify it. From this perspective, it is evident that according to Dewey human (but also animal) mental relations with the environment do not tend towards a faithful mirroring, but rather towards an action from within and a capacity to critically reconsider the action itself when it proves ineffective (this being the distinctively human trait), when the course of action is uncertain and requires an

\footnotetext{
17 From this perspective, we find a convergence with the emphasis placed by enactivists (both in Varela et al. 1991, p. 185 ff.; Gallagher 2017, p. 168) on the notion of exaptation and of the reuse of previous resources for new ends of contemporary evolutionist thought. Obviously, Stephen Gould's work on these issues was unknown to Dewey and the pragmatists, but the reading of Darwin formulated by Chauncey Wright, a former member of the famous Metaphysical Club, already went in this direction. See Parravicini (2012).

18 This is closely reminiscent of the enactivist emphasis on emergent properties. See Varela et al. (1991, p. 88).

19 As is known, this label was used to describe James' and Dewey's psychological theories. We owe to James Rowland Angell, also a member of the Chicago School, the definition of the term: "The functional psychologist then in his modern attire is interested not alone in the operations of mental process considered merely of and by and for itself, but also and more vigorously in mental activity as part of a larger stream of biological forces which are daily and hourly at work before our eyes and which are constitutive of the most important and most absorbing part of our world. The psychologist of this stripe is wont to take his cue from the basal conception of the evolutionary movement, i.e., that for the most part organic structures and functions possess their present characteristics by virtue of the efficiency with which they fit into the extent conditions of life broadly designated the environment. With this conception in mind he [p. 69] proceeds to attempt some understanding of the manner in which the psychical contributes to the furtherance of the sum total of organic activities, not alone the psychical in its entirety, but especially the psychical in its particularities_-mind as judging, mind as feeling, etc." (Angell 1907, pp. 68-69). Therefore, I believe that the characterisation of Dewey's philosophy of mind in functionalist terms is not subject to Gallagher's criticism of Andy Clark's extended mind approach, which would ultimately weaken the specificity of the human body with respect to the development of cognition (Gallagher 2017, p. 36).
} 
analytical reassessment of the elements of an otherwise integral experience in view of further action.

The field of inquiry and inferences opens up here, which is to say-according to Dewey - the field of cognition, understood as a process underway (as opposed to a substance or faculty that can be attributed to a subject). Human interactions with the environment are mental because human beings are capable of changing mere suggestions-whereby something present will suggest something absent, of which it is a sign (smoke suggests fire and is a sign of it)_into meanings. In passing, it may be interesting to note that Dewey speaks of "suggestions" rather than indications in the 1916 Introduction to his Essays in Experimental Logic (Dewey 2004): instead of focusing on object references, Dewey seems to foreshadow the idea that certain things are perceived as suggestions, as invitations to act in a certain manner. ${ }^{20}$ To return to the transition from sign to meaning (from a two-way relation to a three-way one), the external event of smoke does not become mental because an alleged non-physical but psychic image of it is produced in the mind, understood as an inner space; there is no need to posit the duplication of smoke into an internal representation that corresponds to the external phenomenon. In the concrete communicative exchanges in which it appears, the word "smoke" is part of mental behaviour insofar as, in relation to an obstacle or uncertain context, smoke - the sign suggesting fire-comes into play in a cognitive or reflective process of inquiry, whereby it is analytically distinguished and fixed by means of gestures and words that guide the interlocutors' action.

It is evident, therefore, that Dewey's conception of the mental behaviour does not draw any contrast between motor-sensory sense-making and alleged superior modes of cognition (as suggested by Dreyfus 2013; Hutto and Myin 2013). Rather, it implies a re-evaluation of the form and role of conceptual reflection and language in what we might call an enactivist and operative sense, functional to the activity of inquiry in which cognition consists. When Dewey argues that human relations with the environment are mental because they imply the transition from existential indications to conceptual implications, he is drawing upon an operative and non-representational notion of concept, whereby concepts emerge as working hypotheses to identify and select the facts relevant to a given inquiry (Dewey 1991, p. $105 \mathrm{ff}$.; cf. Dreon 2007, p. 173). In other words, they are not generalisations made from facts observed independently of any kind of guideline, but hypotheses that direct the gaze, hands and attention of those who need to solve a practical problem or formulate a theory on certain salient aspects of an inquiry, to the detriment of others.

Moreover, it is clear that according to Dewey the emergence of forms of mental interaction between human beings and their environment is based on language, understood as a meaningful exchange between speakers: not only are words a far more stable means of discriminating and sharing the "suggestions" of signs than gestures, but the natural environment of human beings is social, insofar as their destiny or history depends not just on their individual actions, but also — and especially — on shared activities, on their (peaceful or conflictual) participation in associated forms of life. Verbal language (Dewey 1981, p. 213) is not a means to convey inner representations,

\footnotetext{
20 From this perspective, the transition from "suggestions" to "affordances"- the relevance of which for enactivism is well-known-as invitations to act in a certain way does not seem far-off.
} 
but primarily a means allowing interlocutors to mutually regulate their conduct in view of action: language itself is a kind of communication consisting in vocal gestures, which extends and transforms previous forms of gestural communication, yet still remains - at an embryonic level - a kind of gesture itself, i.e. a kind of action, whose meaning is shared by the speaker and the listener in view of a common practice (Dreon 2018). Words allow us not just to retain the consequences of our previous actions and to anticipate the results of future ones, but also to recall and foresee the effects of other people's behaviour: what language conveys is the world of others, of our fellow-humans, rather than a thought activity occurring primarily within our own minds or the neural computation of a brain cut off from the rest of the body and the world.

\section{Framing cognition within experience}

Dewey's conception of the interactions between an organism and its environment is evidently reminiscent of the enactivist view that an organism and its environment make up a system characterised by a form of "structural coupling" (Varela et al. 1991, p. 151), whereby the changes occurring in any part of the system affect all other aspects and have repercussions on the system as a whole, whose components dynamically determine themselves according to a reciprocal configuration. ${ }^{21}$ Likewise, it is clear to researchers from both traditions that pragmatism and enactivism share a continuist conception of cognition and life phenomena, which is to say a non-reductionist form of naturalism (Colombetti 2014, p. XVI; Gallagher 2017, p. 36) or "cultural naturalism" (Dewey 1991, pp. 26-28). According to this conception, there is no need to invoke factors external to nature to explain the emergence of rationality in the world, as is instead the case if we set off from the assumption of a genuine ontological break between the mind and the world (Margolis 2002, pp. 6-7). ${ }^{22} \mathrm{New}$ ways of organising the interactions between organisms and the environment - mental ones in this particular case-emerge from existing organic and environmental resources-physiological and neurophysical resources, but also social and cultural ones, among others. However, the innovative configurations taken by these transactions bring out properties that are irreducible to the sum of pre-existing factors, as stressed by the explicitly emergentist option of enactivism, which is already present—albeit not technically laid out-within classical pragmatism. Indeed, I would argue that the latter is more capable of deriving the ultimate consequences from this, by bringing into focus the irreversibility and loop effect of the changes introduced by the emergence of conceptuality and language as properties arising from the previous forms of interaction-I will return to this point in the next section.

\footnotetext{
21 Varela, Thompson and Rosch speak of the selection of salient environmental features by organisms as a form of interpretation (Varela et al. 1991, p. 156).

22 In my view, this is the aspect of cultural naturalism closest to the enactivist concepts of autopoiesis and autonomy, as they regard the organism-environment system, rather than only the individual organisms involved. See Varela et al. (1991, p. 103 and p. 156) and Colombetti (2014, p. 15-19).
} 
Dewey and all classical pragmatists ${ }^{23}$ believe that human cognitive capacities are continuous with the highly complex, multilayered and non-linear functioning of neural processes (Varela et al. 1991, p. $85 \mathrm{ff}$.), as well as with other corporeal resources-e.g. the motor and phonatory resources exclusive to a two-footed organism that can use its hands for manipulation and action, and is provided with a lowered and elongated larynx, capable of far subtler and more complex vibrations than that of any other mammal (Gallagher 2017, p. $164 \mathrm{ff}$.). In turn, this is only one small part of the range of factors that must be taken into account in order to understand human rationality, which appears to be the result of the development of these and other corporeal and behavioural resources and of their mutual adjustment within the highly social structure of the human-environment. ${ }^{24}$ Human rationality cannot be reduced to the mere sum of individual resources-corporeal resources, including neurological, behavioural and environmental ones. Rather, Dewey, like the fathers of enactivism, understands human rationality as the new dynamic and reciprocal configuration of these factors-something wholly contingent and open to further changes, yet irreversible.

A significant point of divergence lies in the fact that-in contrast to the enactivists' primary focus on cognition-Dewey constantly strove to redefine the notion of experience in such terms, by contrast to the solipsistic, associationist and intellectualistic conception of experience developed by modern thought (Dewey 1980a). Experience is the key notion for Dewey, who in a well-known passage of Experience and Nature — echoing James' Essays in Radical Empiricism — defines it not as a subjective phenomenon occurring within one's own consciousness, but as "a doublebarrelled word", which encompasses what human beings do and endure, what they fight for and believe in, as well as the ways in which they act and undergo things, enjoy, believe and suffer (Dewey 1981, p. 18). Dewey goes on to explain that experience includes both things in the world - the changes of day and night, cold and heat that the farmer fears or desires-and he who plants seeds, tills the fields, and resorts to magic or chemistry to protect his harvest. I would not rule out that this rather oldfashioned way of putting things was a means for Dewey to affirm the need to bring theory back to ordinary, everyday practices, in opposition to the idea of philosophy as a self-referential practice. ${ }^{25} \mathrm{Be}$ that as it may, the passage emphasises the primacy of the experiential relation over its parts - the primacy of the interaction itself over the organism and the environment within which it develops-along with the idea of the

\footnotetext{
${ }^{23}$ See William James's emphasis—already in Principles of Psychology —on the plasticity of the nervous system, understood not as a machine with pre-installed programmes that functions autonomously, but as a sound board that configures itself through the reverberation of environmental events (see esp. the chapter on habits and the one on emotions).

${ }^{24}$ In this respect, Dewey and Mead's pragmatism would appear to foreshadow Tomasello's conclusions regarding the social dimension of the evolution of human culture, as well as his thesis that human cognitive evolution is largely based not just on biological resources, but also on cultural resources (Tomasello 1999). On this point, see Dreon (2019a).

25 Dewey's claims against armchair philosophy did not prevent him, however, from drawing upon Hegel-as well as James. I believe that the influence of Hegelian thought is visible in the passage just quoted, if only in naturalised form (Rorty 1991), whereby the truth is the whole and not the isolated part, which instead coincides with the abstract truth in Hegel's philosophy. In addition, it is important to recall the notion of Erfahrung, which in the Phenomenology of the Spirit plays a crucial role, to the detriment of the subjectivist idea of experience associated with the history of the term Erlebnis.
} 
relation between human beings and the world in terms of praxis and action, rather than in terms of an inert mirroring of reality by a disembodied consciousness. Dewey sought to question the primacy traditionally assigned in modern philosophy to consciousness over experience, whereby knowing tends to reduce experience to the translation of the ontological problem - the alleged ontological rift between the subject and physical reality-into an epistemological problem-how the subject can know external reality.

This criticism is not exclusively aimed at the alleged primacy of knowledge, conceived in representational terms. Dewey envisages cognition as an actively engaged process of inquiry within the environment, thereby foreshadowing the enactivist idea that cognition is an engagement in the world. At the same time, he conceives cognition as a fully-embodied and fully-emebedded process, which revolves around the physiology of the brain and motor-sensory coordination, as well as available environmental resources-not just natural resources in the case of the human form of life, but also social and cultural ones (Dewey 1991, pp. 30 and ff., 48 and ff.). ${ }^{26}$ Cognition is a crucial part of experience, yet it is neither paradigmatic nor primary (Dewey 1981, p. 28); most importantly, it does not exhaust the richness and variety of experience. In particular, as stressed in the introduction to the Essays in Experimental Logic (Dewey 2004), cognition is an intermediate stage, whose results must also be regarded as intermediate, which is to say as the outcomes of an inquiry rather than as the true nature of the everyday things we find ourselves dealing with (see Dewey 1981, p. 10 and ff.; 1988, p. 10).

As already noted, human structural interactions with the environment become cognitive when the situations become indeterminate, when it is difficult to know how to act, when our usual response habits do not work and we need to reconsider them analytically and come up with a new creative hypothesis to solve the impasse (Dewey 1991, p. 109 and ff.). What this means is that cognitive processes-be they resolutions of practical, everyday problems, or formulations of highly sophisticated theories-emerge out of a pre-existing web of thick relations between events, individuals, histories, natural aspects and cultural meanings that are already given:

the intellectual element is set in a context which is noncognitive and which holds within it in suspense a vast complex of other qualities and things that in the experience itself are objects of esteem or aversion, of decision, of use, of suffering, of endeavor and revolt, not of knowledge (Dewey 2004, p. 3).

This qualitative density of our everyday experience (which Dewey describes as "esthetic" in many passages of Experience and Nature: Dewey 1981, p. 70 ff.), its vagueness and plurality, is something Dewey wishes to safeguard against the excessive power that philosophy has generally attributed to knowledge. Cognition springs from the difficulties encountered in these pre-existing, qualitatively saturated contexts and responds to them through processes of analytical discrimination that require both synthetic gestures and the imagination to identify a solution (Maddalena 2015). The effectiveness of these processes can only be measured through a return to the nonreflective phases of experience, through the crystallisation of the results of previous

\footnotetext{
26 This is also clear to many scholars from the enactivist camp and, more generally, to all theorists of the embodied, embedded, extended and enactive mind (Clark 2006; De Jaegher and Di Paolo 2007; Spurrett and Cowley 2010; Gallagher 2013; Krueger 2013; Fusaroli et al. 2014).
} 
inquiry into habits of action and beliefs, into new gestures and words, into more or less shared practices and unwritten norms-i.e. into a pervasive material culture, rather than a body of propositional contents that are first developed and stored in the alleged inner theatre of the mind.

I do not know whether this kind of restriction of the notion of cognition compared to the broader idea of experience can lead to the more effective development of empirical research programmes. However, I believe that this kind of approach to cognition offers a different perspective on one of the most recent problems in the cognitive sciences, namely that of the applicability of an enactive and non-representational concept to higher forms of knowledge that are not as basic as perception and motor action. This problem will be the starting point of the next section.

\section{A virtuous circularity}

One of the most widely debated points in enactivist literature in recent years (Hutto and Myin 2013; Gallagher 2017, p. 187 ff.) has been the need to respond to the objection that while the enactivist approach is an effective one to interpret basic cognitive processes, namely perception and motor action, it can hardly be applied to higher cognitive processes, such as memory, the imagination, reflection and judgement. Even radical enactivism (Hutto and Myin 2013) confirms this distinction between lowerlevel cognitive activities, in relation to which any representational analysis is ruled out, and higher-level cognitive activities, which instead would imply propositional representational contents, in particular because they entail the use of language as a means to scaffold memory and the imagination. In such cases, propositional attitude explanations would be appropriate, but these representationally based modes of thinking would emerge late on both the ontogenic level and the phylogenetic one (Hutto and Myin 2013, pp. 13-15). ${ }^{27}$ The problem of scaling up enactivism to higher-level cognitive forms is intertwined with the debate which, since 2005, has pitted Hubert Dreyfus and John McDowell against one another (now in Schear 2013) with regard to the so-called myth of the mental: in brief, Dreyfus has argued that human perception and motor action rule out any mental content and conceptuality, whereas McDowell contends that all forms of human experience, including the motor-sensory exploration of our surroundings, fall within the space of reasons, and are therefore conceptual and rational (McDowell 2013).

This debate presents some similarities with the "scaling up" issue in enactivism: should we assume that there is a basic discontinuity between low-order cognitive processes and higher cognitive activities, depending on the intervention of representations as structural elements of higher forms of cognition? Similarly, is there a gap between an embodied coping with the world and discursive and normative practices, because of their being scaffolded by conceptual reason and speech? Moreover, what kind of relationship exists between the two sides of the above-mentioned oppositions? Should we assume that there is a one-directionally foundational connection between embodied

\footnotetext{
27 It must be recalled, however, that non-representational explanations are possible even in the case of high-level cognitive processes, according to Daniel Hutto. See Hutto (2017) on the role of narrativity in autobiographical memory.
} 
coping with the environment and discursive practices, as well as between embodied, enacted sense-making and the imagination, memory, and judgment?

A rigid opposition between the two poles of the alternative seems problematic from Dewey's perspective, since he envisages the emergence of human mental behaviour in close connection to language. ${ }^{28}$ What is also unacceptable from Dewey's point of view is the implicit assumption that in relation to the human world we must posit a linear order between the two kinds of process, whereby higher-level cognitive activities are founded on basic cognitive processes. On the other hand, this does not mean that Dewey slips into a form of neo-Kantian transcendentalism - something deeply foreign to him (see Margolis 2017, pp. 37, $47 \mathrm{ff}$.) —-since he steers well clear of both the kind of over-intellectualising of human rationality and language that McDowell and Brandom have been accused of Noë (2013), Zahavi (2013) and Gallagher (2017, p. 202), and of any transcendental apriorism of the intellect and language.

But let us keep to the reasons why the aforementioned distinction is a problematic one for Dewey. First of all, according to Dewey "the occasions in which a human being responds to things as merely physical in a purely physical way are comparatively rare"- - examples would include someone reacting to a loud noise with a startled leap or someone touching a burning object and immediately withdrawing his or her hand. Dewey notes that "the typical cases of human behavior are not represented by such examples" (Dewey 1991, p. 48). These cases are not typical of human behaviour because human actions occur in an environment that, right from one's birth, is shared with other individuals, who contribute to the configuration and transmission of a culture. This social and cultural environment, consisting not so much of informative contents to be transmitted but rather of behavioural habits already in use, precedes and shapes all human behaviours and influences even the more instinctive ones (Dewey 1983, p. 104 ff.). According to Dewey-who was a keen observer of children's behaviour ${ }^{29}$ and shared Mead's deep interest in social psychology, as well as in the ontogenesis of human behaviours - the reason for this has to do with the kind of embodiment typical of mammals such as ourselves, i.e. the marked immaturity of the human newborn, who requires the care of his or her fellow humans in order to survive for a much longer period of time compared to non-human mammals (Dewey 1983, pp. 43-45). This long stage of acute dependence exposes the newborn to other people's behavioural habits long before he or she is capable of configuring his or her own (Mead 2011, p. 73) both at a motor and at a neural level (James 1981, ch. IV).

Culture and gestural and verbal communication are therefore understood as a range of practices designed to affectively regulate social bonds and shared action. From a pragmatist perspective, they do not constitute a transcendental horizon of any form of commerce with the world (including the motor-sensory one), but rather the naturally cultural environment that has configured itself in such a way owing to the fully contingent yet irreversible physiognomy acquired by human phylogenesis. In other words, the pragmatist approach leads us to consider the consequence even on the level of human perception and motor action of an ecological niche marked by complex

\footnotetext{
28 The same doubt is also voiced by Steiner (2014, p. 46).

29 This is shown not just by Dewey's pedagogical interests but also by his personal experience, as we read in Dyehouse and Manke (2017).
} 
forms of cooperative action, culturally and linguistically shaped (see Clark 2006). If the phenomenon of coupling is structural to organic-environmental systems, can we conclude that human perception and our motor orientation in the world remain unvaried compared to previous forms of animal sensibility when the environmental conditions in which we operate become cultural, meaningful and largely linguistic? If I am reading Dewey correctly, from his point of view the mental connotation acquired by human conduct compared to forms of subtle sensibility already present in other organic forms is bound to engender a reconfiguration, given the weight of the sociocultural, linguistic and meaningful conditions of the human-environment.

I believe that such conclusions impose themselves, once we consider the emergentist assumptions common to both pragmatism and enactivism - and this leads us back to the argument I had anticipated in the previous section. An emergent property-in Dewey's case, the mental mode of interaction between human organisms and their environment-is not merely a property that, while resting on the internal resources of the system, produces a new organisation of the system itself, which cannot be reduced to the sum of factors from which it springs. The new organisation, or new property, becomes one of the factors of the system itself and retroacts on it: it produces loop effects that affect the previous configurations of the system. In the case under scrutiny, for example, we have the acute sensibility - in itself already an animal trait - that guides the movement of the newborn's mouth towards his or her mother's breast, for which the newborn displays a marked predilection right from the start. Nonetheless, we should take into account that this behavioural predisposition in humans is embedded in the peculiar form of gestural communication between mother and infant from the very beginning (Trevarthen 1979; Stern 1985; Falk 2004; Dissanayake 2011): motherese-a largely affectively based, multimodal and qualitatively rich kind of language — orients the gaze of the infant as well as his or her hands and arm movements. Of course, gestural communication between mother and infant are not equivalent to the space of reasons, and baby-talk is not a sum of propositions conveying information about the external reality. Still, they constitute the socio-affective and incipiently cultural environment in which neonate's perceptions and movements configure themselves.

I should stress that this obviously implies a non-representational conception of culture, cognition and even human communication, which probably converges with the direction suggested in the last chapter of Shaun Gallagher's book, namely the scaling down of memory, the imagination, reflection and in general the idea of human rationality (Gallagher 2017, p. 191). For example, regarding the imagination, Gallagher says that we should problematize the traditional conception of it as a purely mental process based on belief representations. On the contrary, the imagination could be considered a kind of activity having in view a variety of possible actions and, consequently, actively engaged in the identification of possible physical, social or cultural affordances in a given context (Gallagher 2017, p. 195). It would be better to assume that "the imagination is not something that happens in the head"; on the contrary, it "involves embodied action, using toys, props, artefacts, instruments, and so on" (Gallagher 2017, p. 193), as happens when kids play pretend. Dewey made a somewhat similar point in his Ethics, when characterizing the process of moral evaluation as "dramatic rehearsal", rather than as a purely intellectual judgment, and comparing 
it to a kind of mimetic performance of alternative lines of behaviour (Dewey 1978, p. 292).

From this perspective, the development of an enactivist conception of language might represent a new goal. ${ }^{30}$

Moving towards a conclusion, does this mean that we must abandon any distinction between more complex forms of cognition and more elementary ones? Obviously, it cannot be denied that there exist different degrees of complexity and very different forms of cognition. Moreover, Dewey constantly recalls that not all our experiences are cognitive; rather, reflection is one particular, if crucial, form among other forms taken by our interactions with the environment in given circumstances.

From this perspective, it might also be useful to return to a couple of aforementioned distinctions suggested by the pragmatist philosopher, in order to formulate them more explicitly.

First of all, Dewey distinguishes between, on the hand, the primary experience of those things which absorb us and are immediately experienced through the way they affect us - we desire or fear them, find them disturbing or agreeable, are bothered by or indifferent to them-and, on the other, the occasions in which we postpone their impact on our lives and the consummation of an experience in order to consider such things in view of other possible ones (Dewey 1981, p. 71). In other words, Dewey maintains that cognitive processes - which nonetheless remain oriented towards action and aimed, albeit indirectly, at restoring a dynamic balance between the components of ongoing experience-emerge out of a qualitative background, which he calls "esthetic" insofar as it primarily refers to sensibility, understood as the affective impact which an event, another person's action or a given state of affairs produces on us. ${ }^{31}$ At first sight, this distinction might recall the one drawn by Dreyfus, who in keeping with the phenomenological tradition opposes skilful coping, which absorbs us without requiring the intervention of discursive rationality, and reflective thought (Dreyfus 2007, p. 354). However, the similarity is only apparent, since Dewey constantly emphasises the fact that the results of previous inquiries return, through a circular movement, to qualitative, non-reflective experience, within which they become entrenched and absorbed. For this reason, it is important to note that inquiry is cognition understood as an ongoing process, designed to modify the organic and environmental conditions of a previous interaction in order to find a way out of the crisis that has engendered it (Dewey 1988, p. 6). But knowledge, as the sum of the collective results of previous inquiries, becomes settled in qualitative experience, which it enriches or impoverishes, by modifying the conditions by which things prove disturbing or agreeable to us. Therefore, in The Need for a Recovery of Philosophy Dewey can argue that experience is full of inferences (Dewey 1980a, b): not because it is invariably cognitive, or

\footnotetext{
30 On Dewey's conception of language see Dreon (2014). On Mead's view of language see Dreon (2019). When I was correcting the last draft of my text for publication in this journal issue, the promising book Linguistic Bodies. The Continuity Between Life and Language by Ezequiel Di Paolo, Elena Cuffari and Hanna De Jaegher was published. It will deserve great attention in the ongoing debate between enactivism and the pragmatist heritage.

31 I believe that with regard to this point a convergence can be found with the notion of primordial affectivity developed by Colombetti (2014). On the topic of emotions and affective sensibility in classical pragmatism, see Dreon (2019b).
} 
because it primarily revolves around inner mental representations, but rather because the outcomes of previous reflective processes become entrenched as common practices and shared or idiosyncratic usages and habits of behaviour, action and thought that are nonetheless engaged out there, in the world-reconfiguring the very conditions of non-reflective experience through a shared cultural heritage. The distinction between qualitative experience, absorbed in dealings with the world, and cognition is not foundational or hierarchical, but circular and dynamic, as well as functional to the context of inquiry within which this very distinction is drawn (Dewey 2004, p. 12). Or perhaps we might describe it as dialectic, to recall Dewey's anti-metaphysical and naturalising use of Hegelian thought.

\section{Conclusions}

By taking as given the convergence between Dewey and the enactivist approach to cognition as the fully embodied action occurring not within a separate mind but in an environment that determines it and at the same time is reconfigured by it, I have chosen to focus on certain aspects that can foster a fruitful engagement with enactivism. First, I briefly outlined the philosophy of mind developed by the pragmatist philosopher. I argued that his anti-substantialist, continuistic and emergentist conception of the mind — but we should really say "the mental" — as a typically human conduct not only undermines the representationalist approach to cognition, but leads to a profound rethinking of conceptuality and language. I then emphasised that in Dewey's philosophy cognition is regarded as an internal and intermediate phase of experience, because the pragmatist philosopher contends that the interactions between human organisms and their environment includes many different forms of interaction and a qualitative richness that is not exhausted by the concept of cognition. Finally, I argued that from Dewey's perspective it is problematic to draw a clear-cut distinction between, on the one hand, perception and motor action as basic cognitive activities — which would rule out all forms of representation and discursiveness - and, on the other, the imagination, memory, reflection and discursive judgement as high-level cognitive activities - which would instead be based on conceptual and linguistic resources. From this point of view, it seems necessary to consider the consequences of the social, cultural and linguistic characterisation of the human ecological niche for an approach based on the idea that the organism and its environment constitute a system of mutual determination. I have further suggested that the adoption of a circular and dynamic, non-foundational, distinction between qualitative experience and cognition can ensure a less rigid account of the structural coupling of human life forms with a naturally social and cultural environment.

\section{References}

Angell, J. R. (1907). The province of functional psychology. The Psychological Review, XIV(2), 61-91. Arteaga, A. (2017). Embodied and situated aesthetics. An enactive approach to a cognitive notion of aesthetics. Artnodes, 20, 20-27. 
Calcaterra, R. M. (2011). Varieties of synechism. Peirce and James on mind-world continuity. Journal of Speculative Philosophy, 25(4), 412-424.

Clark, A. (2006). Language, embodiment, and the cognitive niche. Trends in Cognitive Neurosciences, 10(8), 370-374.

Colombetti, G. (2014). The feeling body. Affective science meets the enactive mind. Cambridge: MIT Press.

Cometti, J. P. (2015). Making the difference: John Dewey and the naturalization of aesthetics. Aisthesis, $8(1), 123-134$.

De Jaegher, H., \& Di Paolo, E. (2007). Participatory sense-making. An enactive approach to social cognition. Phenomenology and the Cognitive Sciences, 6, 485-507.

Dewey, J. (1972). The reflex-arc concept in psychology. Volume 5 of the early works. Carbondale: Southern Illinois U.P.

Dewey, J. (1978). Ethics. Volume 5 of the middle works. Carbondale: Southern Illinois U.P.

Dewey, J. (1979). What are states of minds? Volume 7 of the middle works (pp. 31-43). Carbondale: Southern Illinois U.P.

Dewey, J. (1980a). The need for a recovery of philosophy. Volume 10 of the middle works (pp. 3-48). Carbondale: Southern Illinois U.P.

Dewey, J. (1980b). The need for social psychology. Volume 10 of the middle works (pp. 53-63). Carbondale: Southern Illinois U.P.

Dewey, J. (1981). Experience and nature. Volume 1 of the later works. Carbondale: Southern Illinois U.P.

Dewey, J. (1983). Human nature and conduct. Volume 14 of the middle works. Carbondale: Southern Illinois U.P.

Dewey, J. (1985). Ethics. Volume 7 of the later works. Carbondale: Southern Illinois U.P.

Dewey, J. (1988). Experience, knowledge, and value. A rejoinder. Volume 14 of the later works (pp. 3-90). Carbondale: Southern Illinois U.P.

Dewey, J. (1989). Art as experience. Volume 10 of the later works. Carbondale: Southern Illinois U.P.

Dewey, J. (1991). Logic: The theory of inquiry. Volume 12 of the later works. Carbondale: Southern Illinois U.P.

Dewey, J. (2004). Essays in experimental logic. New York: Dover Publication.

Dewey, J. (2007). The influence of Darwin on philosophy. In L. Hickman (Ed.), The influence of Darwin on philosophy and other essays in contemporary thought (pp. 5-12). Carbondale: Southern Illinois U.P.

Dissanayake, E. (2011). Prelinguistic and preliterate substrates of poetic narrative. Poetics Today, 32(1), 55-79.

Dreon, R. (2007). Esperienza e linguaggio: Le risposte del "naturalismo culturale” di Dewey. In R. Dreon (Ed.), Il sentire e la parola (pp. 165-207). Mimesis: Milano-Udine.

Dreon, R. (2014). Dewey on language: Elements for a non-dualistic approach. European Journal of Pragmatism and American Philosophy, VI(2), 109-124.

Dreon, R. (2018). Is there any room for immediate experience? Looking for an answer in Dewey (and Wittgenstein) via Peirce and James. Pragmatism Today, 9, 59-73.

Dreon, R. (2019a). Gesti emotivi e gesti verbali. L'eredità di George Herbert Mead sulla genesi del linguaggio umano. Sistemi intelligenti, I, 115-133.

Dreon, R. (2019b). A pragmatist view of emotions. Tracing its significance for the current debate. In L. Candiotto (Ed.), Emotions for knowledge (pp. 73-99). London: Palgrave.

Dreyfus, H. (2007). Why Heideggerian AI failed and how fixing it would require making it more Heideggerian. Philosophical Psychology, 20(2), 247-268.

Dreyfus, H. (2013). The myth of the pervasiveness of the mental. The McDowell-Dreyfus debate. In J. K. Schear (Ed.), Mind, reason, and being-in-the-world (pp. 15-40). London: Routledge.

Dyehouse, J., \& Manke, K. (2017). The philosopher as parent: John Dewey's observations of his children's language development and the development of his thinking about communication. Education and Culture, 33(1), 18-34.

Falk, D. (2004). Prelinguistic evolution in early hominins: Whence motherese? Behavioral and Brain Sciences, 27, 491-503.

Fusaroli, R., Gangopadhyay, N., \& Tylén, K. (2014). The dialogically extended mind: Language as skillful intersubjective engagement. Cognitive Systems Research, 29(30), 31-39.

Gallagher, S. (2013). The socially extended mind. Cognitive Systems Research, 25(26), 4-12.

Gallagher, S. (2017). Enactivist interventions. Rethinking the mind. Oxford: Oxford U.P.

Hildebrand, D. (2003). Beyond realism and antirealism: John Dewey and the neopragmatists. Nashville: Vanderbilt U.P. 
Hutto, D. (2017). Memory and narrativity. In S. Bernecker \& K. Michaelian (Eds.), The routledge handbook of philosophy of memory (pp. 192-204). London: Routledge.

Hutto, D., \& Myin, E. (2013). Radicalizing enactivism. Basic minds without content. Cambridge: MIT Press.

James, W. (1981). Principles of psychology. In F. H. Burkhardt, F. Bowers, \& I. K. Skrupskelis (Eds.), The works of William James. Cambridge: Harvard University Press.

Johnson, M. (2010). Cognitive science and Dewey's theory of mind, thought, and language. In M. Cochran (Ed.), The Cambridge companion to Dewey (pp. 123-144). Cambridge: Cambridge University Press.

Krueger, J. (2013). Ontogenesis of the socially extended mind. Cognitive Systems Research, 25(26), 40-46.

Maddalena, G. (2015). The philosophy of gestures. Completing pragmatists' incomplete revolution. Montreal: McGill-Queen's University Press.

Madzia, R., \& Jung, M. (Eds.). (2016). Pragmatism and embodied cognitive science. From bodily intersubjectivity to symbolic articulation. Berlin: De Gruyter.

Madzia, R., \& Santarelli, M. (Eds.). (2017). Pragmatism, cognitive science and the sociality of conduct. Pragmatism today (Vol. 8, No. 1). Europe: Central European Pragmatist Forum.

Margolis, J. (2002). Reinventing pragmatism. American philosophy at the end of the twentieth century. London: Cornell U.P.

Margolis, J. (2017). Three paradoxes of personhood. In R. Dreon (Ed.), The venetian lectures. Milano: Mimesis International.

McDowell, J. (2013). The myth of the mind as detached. In J. K. Schear (Ed.), Mind, reason, and being-inthe-world. The McDowell-Dreyfus debate (pp. 41-58). London: Routledge.

Mead, G. H. (2011). Deegan, M. J. (Ed.), Essays in social psychology. London: Transaction Publishers.

Menary, R. (2015). Pragmatism and the pragmatic turn in cognitive science. In A. K. Engel, K. J. Friston, \& D. Kragic (Eds.), The pragmatic turn. Toward action-oriented views in cognitive sciences (pp. 215-234). Cambridge: MIT Press.

Noë, A. (2013). On overintellectualizing the intellect. In J. K. Schear (Ed.), Mind, reason, and being-inthe-world: The McDowell-Dreyfus debate (pp. 178-193). London: Routledge.

Parravicini, A. (2012). Il pensiero in evoluzione. Chauncy Wright tra darwinismo e pragmatismo. Pisa: ETS.

Peirce, C. S. (1992a). Questions concerning certain faculties claimed for man (1868). In N. Houser \& C. Kloesel (Eds.), The essential peirce (1867-1893) (Vol. 1, pp. 11-27). Bloomington: Indiana University Press.

Peirce, C. S. (1992b). Some consequences of four incapacities (1868). In N. Houser \& C. Kloesel (Eds.), The essential peirce (1867-1893) (Vol. 1, pp. 28-55). Bloomington: Indiana University Press.

Rorty, R. (1991). Lumps and texts. In R. Rorty (Ed.), Objectivity, relativism, and truth (pp. 78-92). Cambridge: Cambridge University Press.

Schear, J. K. (Ed.). (2013). Mind, reason, and being-in-the-world. The McDowell-Dreyfus debate. London: Routledge.

Solymosi, T., \& Shook, J. (Eds.). (2014). Neuroscience, neurophilosophy and pragmatism. Brains at work with the world. London: Palgrave Macmillan.

Spurrett, D., \& Cowley, S. (2010). The extended infant: Utterance-activity and distributed cognition. In R. Menary (Ed.), The extended mind (pp. 295-323). Cambridge: The MIT Press.

Steiner, P. (2008). Délocaliser les phénomènes mentaux: La philosophie de l'esprit de Dewey. Revue Internationale de Philosophie, 62(245, 3), 273-292.

Steiner, P. (2014). Enacting anti-representationalism. The scope and the limits of enactive critiques of representationalism. Avant, 5(2), 43-86.

Steiner, P. (2017). Pragmatism in cognitive science: From the pragmatic turn to Deweyan adverbialism. Pragmatism Today, 8(1), 9-27.

Stern, D. (1985). The interpersonal world of the infant. New York: Basic Books.

Tomasello, M. (1999). The cultural origins of human cognition. Cambridge: MIT Press.

Trevarthen, C. (1979). Communication and cooperation in early infancy: A description of primary intersubjectivity. In M. Bullowa (Ed.), Before speech. The beginning of interpersonal communication (pp. 321-348). London: Cambridge U.P.

Varela, F. J., Thompson, E., \& Rosch, E. (1991). The embodied mind: Cognitive science and human experience. Cambridge: MIT Press.

Zahavi, D. (2013). Mindedness, mindlessness and first-person authority. In J. K. Schear (Ed.), Mind, reason, and being-in-the-world: The McDowell-Dreyfus debate (pp. 320-340). London: Routledge. 
Publisher's Note Springer Nature remains neutral with regard to jurisdictional claims in published maps and institutional affiliations. 